\title{
Effect of terazosin hydrochloride in airways of patients with bronchial asthma
}

Shaip Krasniqi, Hilmi Islami

Institute of Pharmacology and Toxicology and Clinical Pharmacology, Faculty of Medicine, University of Prishtina "Hasan Prishtina”, Prishtina, Albania

Submitted: 15 July 2016

Accepted: 6 August 2016

Arch Med Sci Civil Dis 2016; 1: e81-e86

DOI: 10.5114/amscd.2016.62219

Copyright (c) 2016 Termedia \& Banach

\section{Abstract}

Introduction: This study aimed to determine the potential effect of terazosin hydrochloride on bronchodilatation and compare it with the agonist effect of salbutamol in patients with asthma and bronchial hyperreactivity. Material and methods: Twelve patients with the diagnosis of asthma and increased bronchial hyperreactivity were enrolled in an open label cohort study. We registered the functional pulmonary parameters by body plethysmography, including airway resistance, intrathoracic gas volume and specific resistance in each clinical subject. Terazosin hydrochloride was orally administered in the dosage of $1 \mathrm{mg}$ and $2 \mathrm{mg}$ tablets.

Results: The results of this study performed in patients with bronchial asthma and hyperreactivity showed that the blockade of specific $\alpha_{1}$-adrenergic receptors with terazosin hydrochloride (1 $\mathrm{mg}$ and $2 \mathrm{mg}$, oral tablets) did not change significantly $(p>0.1)$ bronchomotor tone of the tracheobronchial system compared with the group of patients treated with salbutamol (specific agonist of $\beta_{2}$-adrenergic receptors). The arterial blood pressure decreased slightly, but not significantly, after use of $1 \mathrm{mg}$ and $2 \mathrm{mg}$ tablets of terazosin hydrochloride.

Conclusions: The results of the study show that the activity of specific $\alpha_{1}$-adrenoreceptors in tracheobronchial smooth muscle tone is not the primary mechanism for bronchorelaxation in patients with increased bronchial reactivity. The antagonism of $\alpha_{1}$-adrenoreceptors has a minor impact on the tracheobronchial tone compared with the agonist effect of $\beta_{2}$-adrenergic drugs, which cause a significant decrease in specific resistance of airways.

Key words: terazosin hydrochloride, salbutamol, $\alpha_{1}$-adrenoreceptors, asthma.

\author{
Corresponding author: \\ Hilmi Islami \\ Institute of Pharmacology \\ and Toxicology \\ and Clinical Pharmacology \\ Faculty of Medicine \\ University of Prishtina \\ "Hasan Prishtina" \\ "Mother Teresa" St \\ Rrethi i Spitaleve, p.n. \\ 10000 Prishtina, Albania \\ Phone: +38 649302676 \\ E-mail: islamihilmi@hotmail. \\ com
}

\section{Introduction}

The function of airway smooth muscle is controlled by different neural, metabolic and mediator mechanisms. The bronchial obstruction of respiratory airways is considered a predominant mechanism in asthma and is postulated by attenuated $\alpha_{2}$-adrenergic inhibition [1].

There are many mediators acting as bronchodilator or bronchoconstrictor agents in tracheobronchial smooth muscle, which exert complex and highly dependent activity to other factors, such as the alpha and beta adrenergic system and vascular factors of airways. The initial triggering mechanisms of pathogenesis of asthma are attributed to unbalanced $\alpha$ and $\beta$-adrenergic regulation of tracheobronchial airways, which activates the vascular changes. The vascular changes in the airway wall are ex- 
pressed by increased vascular flow and microvascular permeability, subsequently followed by edema and increased proliferation of blood vessels [2].

In the process of pathogenesis an important process involves changes in bronchial responsiveness attributed to the modification of $\alpha$ - and $\beta$-adrenergic regulation. The $\alpha$-adrenergic regulation has an impact on the airways' normal function, and it has been asserted that clinical manifestation of asthma could be due to increased $\alpha_{1}$-adrenergic receptor activity in the airways.

It is generally accepted that asthma occurs due to different levels of inhibition of $\beta$-receptors with prevalence of $\alpha$-receptors reflecting the changes in bronchial vascular tone and hyperresponsiveness [3].

B-adrenergic drugs are the most frequently used bronchodilators in asthma and obstructive lung disease [4].

Nevertheless, due to newly developed concepts of regulation mechanisms for airway smooth muscle tone and identification of new targets whose inhibition or activation can relax airway smooth muscle, there is a consensus to direct research in new therapeutic options [5].

In severe asthma the administration of $\alpha_{1}$-adrenergic agonists such are noradrenaline [6], methoxamine [7], and adrenaline [8] has been shown to improve bronchial obstruction, while in the stable mild form of asthma, $\alpha_{1}$-adrenergic agonists may potentiate this obstruction.

Recent evidence indicates that selective blockade of $\alpha_{1}$-adrenoreceptors cause vascular effects that are beneficial for lowering of blood pressure and benign prostatic hypertrophy and have been shown to have an additional metabolic effect in dyslipidemia and diabetes mellitus.

The cardiovascular disease and benign prostatic hypertrophy in some patients may coexist with chronic obstructive pulmonary disease and asth$\mathrm{ma}$, and treatment of such cases is more complex in terms of safety and tolerability of treatment.

There is evidence that phentolamine and indoramin acting as $\alpha_{1}$-adrenergic blocking agents produce mild bronchodilation in patients with obstructive pulmonary disease and abolish the propranolol-induced bronchoconstriction and prevent airway obstruction induced by methoxamine and histamine [9]. However, the bronchodilatation effect in spontaneous asthma is not documented $[10,11]$.

The limited evidence indicates that doxazosin, an orally active selective $\alpha_{1}$-blocker, has no effect on tonus of the airways and is considered as safe treatment in patients suffering from high blood pressure coexisting with asthma. The lack of respiratory effects is also described for prazosin, while similar effects are predicted for terazosin.
Taking into consideration the contradictory results of $\alpha_{1}$-adrenergic blocking agents in asthma and due to the limited human data for these effects, we performed the present study to determine any beneficial effects of terazosin hydrochloride on bronchodilatation of asthmatic patients.

\section{Material and methods}

This study has approval from the Ethics Committee of the Faculty of Medicine, University of Prishtina.

Twelve patients with a diagnosis of asthma and increased bronchial hyperreactivity were enrolled in an open label cohort study. The clinical subjects were treated with terazosin hydrochloride $(1 \mathrm{mg}$ and 2 mg tablets) and salbutamol (2 times inhalation of $0.2 \mathrm{mg}$ ).

The selections of clinical subjects were done according to the study protocol considering the subjective patient history, the laboratory/clinical findings and functional examination of the respiratory tract.

All subjects at a minimum of $48 \mathrm{~h}$ before the testing procedure stopped the use of any bronchodilatory substance. The clinical subjects were informed before participation in this research about two phases of research and the performance of pulmonary functional tests. The clinical subjects have approved their participation and signed the informed consent. The patients had a clinical diagnosis of asthma with or without bronchitis comorbidity.

The mean duration from the first diagnosis of asthma was $11 \pm 6$ years (range: 4-20 years). The mean age of clinical subjects was $44 \pm 7$ years (range: $29-45$ years), while the mean body weight of patients was $70 \pm 7 \mathrm{~kg}$ (range: $65-72 \mathrm{~kg}$ ).

After informed consent, the subjects underwent through functional lung examination in the resting condition and following measurements were taken during lung function tests: vital capacity (VC); forced expiratory volume in the $1^{\text {st }} \mathrm{S}$ $\left(\mathrm{FEV}_{1}\right.$ ); airway resistance (Raw) and intrathoracic gas volume (ITGV).

Furthermore, we analyzed the maximal expiratory flow-volume curve/volume (MEFVC). The MEFVC and enforced vital capacity of the lung were registered in the sitting position of the patient. The patient's airways through the mouthpiece device were linked to the pneumotachograph (for measuring the air flow) and volume integrator (for measuring the air volume).

The MEFVC is registered in an X-Y HewlettPackard printer.

On the vertical axis of the body plethysmograph's curve the flow was plotted while on the horizontal axis the volume parameters were plotted. According to the registered values of MEF in 
$25 \%, 50 \%$ and $75 \%$ of $\mathrm{VC}\left(\mathrm{RME}_{25}, \mathrm{RME}_{50}, \mathrm{RME}_{75}-\right.$ $\mathrm{l} / \mathrm{s})$, we calculated several respiratory parameters. These parameters reflect the mechanical properties of lungs and not the expiratory force, but are more sensitive for measurement of the bronchial reactivity than $\mathrm{FEV}_{1}$. Before the initiation to provoke the bronchoconstriction we defined at least two reproducible curves of MEFVC and we measured the blood pressure and arterial pulse in study subjects.

We analyzed in study subjects the Raw and ITGV. Initially, the clinical subject underwent the adoption process in a hermetically sealed cabin of body plethysmography, and then started breathing through the pneumotachograph tube which had been inserted in the mouth through the mouthpiece device. During inspiration and expansion of the chest the air in the cabin is compressed while that in the lung is decompressed, meaning that the intrathoracic pressure is decreased proportionally with the increase of air pressure in the cabin. During expiration the inverse situation occurs: an increase of intra-alveolar pressure and decrease of air pressure in the cabin of the body plethysmograph. At the end of the expiration phase, when the air flow stops, the air pressure is equilibrated between alveoli, bronchi and mouth, and this is the reason that measurement of air pressure in the mouth at this moment reflects the similar alveolar pressure. The change of air pressure in the mouth is controlled by two sensitive manometers.

The plethysmography method enables the measurement of ITGV, which is volume intrathoracic gas at the time of airflow occlusion. From the calculated ITGV we predict the residual functional capacity and we can obtain the volume of occupied air due to airway obstruction, cystic lung or pneumothorax.

In healthy subjects with normal lung function, the intrathoracic gas volume is equal to the residual functional capacity of the lungs. From the $\beta$ and $\alpha$ angle using the specific table of body plethysmography we calculated the airway resistance and intrathoracic gas volume. From the obtained results of these parameters we can calculate the specific airway resistance (SRaw) $(\mathrm{SRaw}=\mathrm{Raw} \times \mathrm{ITGV})$. For study purposes we analyzed the Raw and SRaw. The examination of bronchial response in different substances was done by measurement of Raw and SRaw, which are more sensitive indicators than the curve of MEFVC. These two parameters are very important parameters of bronchoconstriction and bronchodilation. The values of $R M E_{25}$ and $R M E_{50}$ show that the parameters derived from the flow/volume curve are more sensitive than the classic parameters of spirometric measurement $\left(\mathrm{FEV}_{1}, 100 \times\right.$ $\mathrm{FEV}_{1}$ /forced vital capacity (FVC)). The comparison of direct variables such as Raw and SRaw and indirect predictors of obstruction of airways ( $\mathrm{FEV}_{1}$, $100 \times \mathrm{FEV}_{1} / \mathrm{FVC}, \mathrm{RME}_{25}, \mathrm{RME}_{50}$ ) is very important for patients with asthma and obstructive lung diseases.

The basic and functional parameters of study subjects are presented in Table I.

Within at least $48 \mathrm{~h}$ before the start of the study, the clinical subjects did not receive any of the drugs or substances which affect the results of the examination. Lung function was determined in the silent condition. This determination encompassed the measurement of the slow VC, FEV 1 determined by Godardt Company pneumotest, and afterwards by measuring the resistance of the air flow in the lung (Raw) and ITGV with body plethysmography. From the gained Raw and ITGV results, SRaw was calculated: SRaw $=$ Raw $\times$ ITGV.

In the group of patients with bronchial asthma and increased reactivity $(n=12)$, following measurement of initial respiratory parameters the clinical subjects received the oral terazosin hydrochloride (specific antagonist of $\alpha_{1}$-adrenergic receptors) (tablets of $1 \mathrm{mg}$ and $2 \mathrm{mg}$ ), and we measured the Raw and ITGV after 60, 90 and $120 \mathrm{~min}$, while at the end as a control procedure the aerosol salbutamol (specific agonist of $\beta_{2}$-adrenergic receptors) was administered in a dosage of 2 inhalations $\times 0.2 \mathrm{mg}$ followed by measurement of Raw and ITGV and calculation of SRaw.

We hypothesized that changes in the adrenergic system in the respiratory system followed by administration of a specific antagonist of $\alpha_{1}$-adrenergic receptors are not influential in the pathophysiological process of bronchial asthma, or other pulmonary obstructive disease.

\section{Statistical analysis}

The database was analyzed by the statistical program ANOVA. The results were statistically analyzed using the mean $(x)$, standard deviation (SD), and standard error (SEM), while any differences between study groups treated by terazosin hydrochloride were analyzed using the $t$-test.

\section{Results}

Antagonists of $\alpha_{1}$-adrenergic blocking agents are an important group of drugs [12]. To investi-

Table I. Basic characteristics and pulmonary function in clinical subjects

\begin{tabular}{|lccccccc|}
\hline $\boldsymbol{N}$ & Age [years] & Height [cm] & Mass [kg] & VC (\%) & FEV $(\%)$ & Raw [kPa I/s] & ITGV [l] \\
\hline 6 & $43.11 \pm 1.30$ & $177.14 \pm 1.17$ & $70.11 \pm 0.78$ & $104.11 \pm 3.2$ & $116.35 \pm 3.36$ & $0.14 \pm 0.01$ & $3.99 \pm 0.14$ \\
\hline
\end{tabular}


gate whether $\alpha 1$-adrenergic blocking agents such as terazosin hydrochloride have an impact on bronchotracheal tone we administered terazosin hydrochloride to patients with asthma and bronchial hyperreactivity. Terazosin hydrochloride and salbutamol were well tolerated by human study subjects and no side effects were reported during the study period. Compliance of the study drugs was monitored directly by the investigator and no deflection from the study protocol was observed. After measurement of respiratory parameters in baseline mode the clinical subjects received terazosin hydrochloride in two different doses ( $1 \mathrm{mg}$ and $2 \mathrm{mg}$ ) and in three time intervals (after $60 \mathrm{~min}, 90 \mathrm{~min}$, and $120 \mathrm{~min}$ ), while at the end, 5 min after the last dose of terazosin hydrochloride, salbutamol was administered.

The results of this study performed in patients with bronchial asthma showed that the blockade of specific $\alpha_{1}$-adrenergic receptors with terazosin hydrochloride (1 $\mathrm{mg}$ and $2 \mathrm{mg}$, oral tablets) did not change significantly $(p>0.1)$ bronchomotor tone of the tracheobronchial system compared

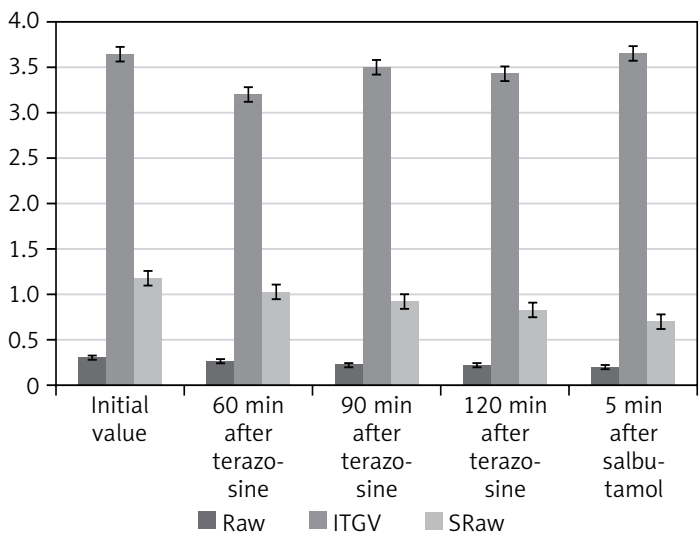

Figure 1. Effect of terazosin hydrochloride (tablets $1 \mathrm{mg}$ - per os) and salbutamol (2 inhalation $x$ $0.2 \mathrm{mg})$; parameters Raw, ITGV and SRaw $(n=6$; $x \pm \mathrm{SEM})$

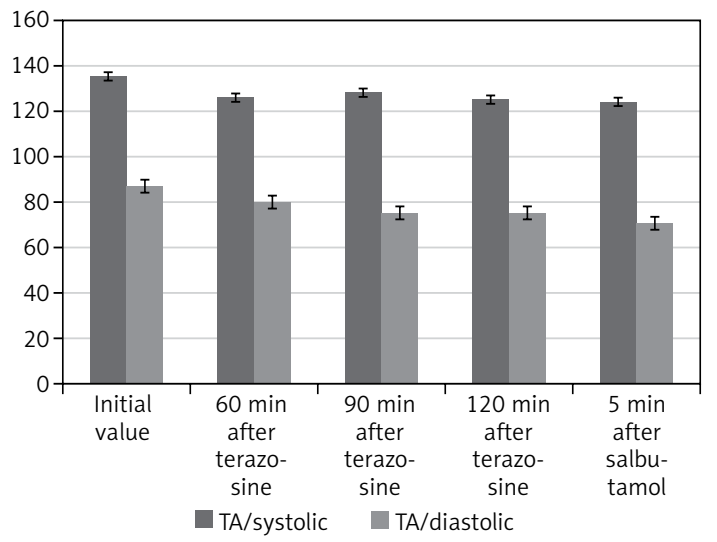

Figure 3. Effect of terazosin hydrochloride (tablets $1 \mathrm{mg}$ - per os) and salbutamol on systolic/diastolic pressure (TA/systolic/diastolic) $(n=6 ; x \pm \mathrm{SEM})$ with the group of patients treated with salbutamol (specific agonist of $\beta_{2}$-adrenergic receptors). The decrease of respiratory parameters (Raw and SRaw) shows the significant bronchodilator response of patients to salbutamol. In contrast, the administered doses of terazosin hydrochloride did not cause significant changes of Raw, ITGV and SRaw values $(p<0.05)$ (Figures 1 and 2).

Moreover, we analyzed the effect of terazosin hydrochloride in doses of 1 and $2 \mathrm{mg}$ and salbutamol on the TA systolic/diastolic pressure.

Terazosin hydrochloride in the oral dose of $1 \mathrm{mg}$ and $2 \mathrm{mg}$, acting as a specific antagonist of $\alpha_{1}$-adrenergic receptors, decreased systolic pressure. The decrease of systolic pressure in patients receiving $1 \mathrm{mg}$ and patients receiving $2 \mathrm{mg}$ was not significant $(p>0.1)$ (Figures 3 and 4). Furthermore, we looked for a difference between terazosin hydrochloride and salbutamol in the systolic/diastolic pressure and no significant changes were revealed.

In summary, we found that terazosin hydrochloride in two different doses showed no changes in

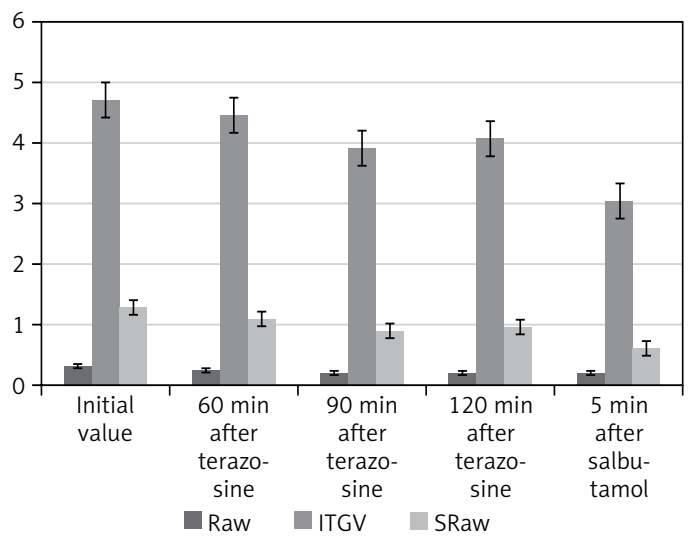

Figure 2. Effect of terazosin hydrochloride (tablets $2 \mathrm{mg}-$ per os) and salbutamol (2 inhalations $\times$ $0.2 \mathrm{mg})$; parameters Raw, ITGV and SRaw $(n=6$; $x \pm$ SEM)

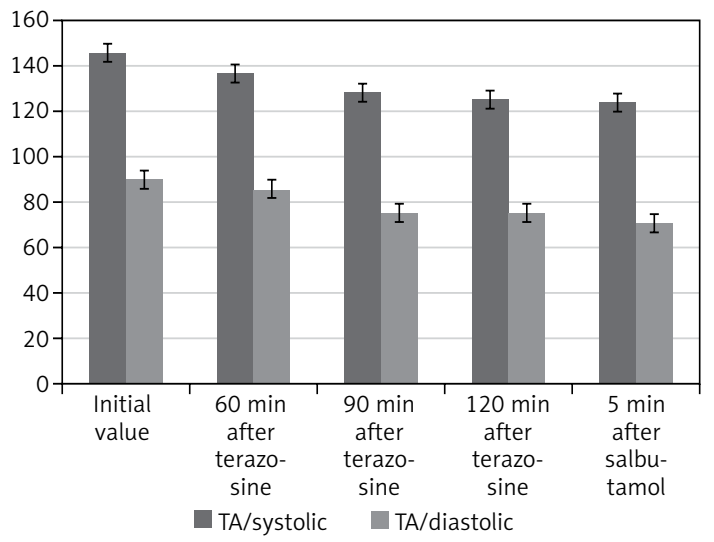

Figure 4. Effect of terazosin hydrochloride (tablets $2 \mathrm{mg}$ - per os) and salbutamol on systolic/diastolic pressure (TA/systolic/diastolic) $(n=6 ; x \pm \mathrm{SEM})$ 
bronchomotor tone of airways. In contrast, salbutamol resulted in bronchorelaxation and improved the measured pulmonary parameters. The administration of terazosin hydrochloride induced a decrease in systolic/diastolic pressure. The decrease of systolic/diastolic pressure in our study was not significantly different between the two doses of terazosin hydrochloride and between terazosin hydrochloride and salbutamol administration.

\section{Discussion}

The use of $\alpha_{1}$-adrenergic blocking agents in treatment of hypertension and congestive heart failure is clearly documented $[12,13]$.

Moreover, the use of these agents is considered as an efficacious and safe treatment for benign prostatic hyperplasia (BPH) [14], and there are new beneficial insights into the metabolic effects of these agents [15].

The use of $\alpha_{1}$-adrenergic blocking agents in general and terazosin in particular is considered safe for patients suffering from asthma without aggravation of bronchoconstriction. Moreover, the use of these agents is considered not to exert any bronchodilatation effects in existing asthma, while there is a controversial conclusion that the effects $\alpha_{1}$-adrenergic blocking agents in asthmatic patients are highly dependent on the hyperreactivity mechanism [16, 17].

The $\alpha_{1}$-adrenergic blockade has no direct and relevant implications in the tonus of smooth muscle of tracheobronchial airways, but the role of $\alpha$-adrenergic receptors in the mechanism of bronchoconstriction cannot be totally excluded. The mechanism of bronchoconstriction mediated by $\beta$-adrenergic blockade in patients with asthma and other chronic obstructive pulmonary disease is not well explained and the effect of activation of $\alpha$-adrenergic receptors should be considered [18].

The oral administration of $1 \mathrm{mg}$ terazosin hydrochloride in our group of patients with asthma and increased bronchial reactivity did not cause a significant decrease $(p>0.1)$ of SRaw. Terazosin does not produce significant changes in respiratory parameters (Raw, ITGV and SRaw) during different time period of study. The effect of terazosin at different times compared with the baseline time (after $60 \mathrm{~min}, 90 \mathrm{~min}$, and after $120 \mathrm{~min}$ ) was the highest at 90 min after administration of therapy, while it was decreased at $120 \mathrm{~min}$, showing the possible mechanism of modulation of $\alpha$-receptors in the airways.

Moreover, we found that the dose of $2 \mathrm{mg}$ of terazosin hydrochloride had a smaller effect on the measured respiratory parameters, which may be as a response of $\alpha$-receptor modulation in this group of patients. Indeed, Vincent et al., in 1992 presented the theory of losing sensitivity of terazosin's $\alpha_{1}$-adrenergic blocking activity, describing the possible mechanism of this phenomenon. One of the plausible mechanisms of this phenomenon was the decrease of affinity of $\alpha_{1}$-adrenergic receptors for terazosin hydrochloride and increase of the dissociation constant $\left(\mathrm{K}_{d}\right)$ for terazosin [19].

Contrary to this conclusion are the findings from Awan et al., which showed that the tolerance to prazosin can be reversed by increasing the dose of the drug [20].

The alternative mechanism for this phenomenon according to some other studies is bronchial hyperresponsiveness, which, it was concluded, may cause the changes of the $\alpha_{1}$-adrenergic blocking agents in the respiratory airways [21].

Nevertheless, Thomson et al. showed that $\alpha_{1}$-receptor activity in bronchial smooth muscle is not the primary mechanism responsible for the variability between asthmatics in nonspecific bronchial hyperresponsiveness [22].

The results of our study showed that terazosin has no effect on the airway performance and is considered safe for treatment of patients with hypertension with co-existing bronchoconstrictive pulmonary disease.

The same results were found in the conclusions in some other similar research, by Biernacki and Flenley [16].

The use of inhaled salbutamol as a $\beta_{2}$-agonist shows a significant decrease in SRaw, with clinical improvement of asthmatic patients with increased bronchial reactivity. This is additional confirmation that $\beta_{2}$-agonists are the most powerful bronchodilators agents and their clinical role is still dominant.

The effect of $1 \mathrm{mg}$ and $2 \mathrm{mg}$ terazosin hydrochloride in the decrease of systolic and diastolic blood pressure in our group of patients showed no significance, and this is contrary to most conclusions of other scientific evidence. The possible explanation in our clinical research is the timing of doses without achieving the titration of maximum dose/clinical response time. The effect of time on the efficacy of $\alpha$-blockers is discussed by Chapman et al., who showed that the timing of doses of $\alpha$-adrenergic blocking agents may affect their efficacy [23].

The exposure time of the patients to terazosin hydrochloride was short and not sufficient for titration of the dose effect of this agent to blood pressure.

The effect of salbutamol on the mean value of systolic and diastolic pressure of patients was not significant and was without clinical relevance.

In conclusion, no specific activity of $\alpha_{1}$-adrenergic receptors in smooth muscle of respiratory airways was observed. We postulate that the effect 
of an $\alpha_{1}$-adrenergic receptor antagonist in asthmatic hyperreactivity patients is not the primary mechanism and use of a $\beta$-agonist still remains the main therapeutic approach in this group of patients.

We predict the possibility of existence of $\alpha_{1}$-adrenergic subreceptors in respiratory airways which have more complex structural content and function, without the capacity to interact significantly with an $\alpha_{1}$-adrenergic receptor antagonist such as terazosin hydrochloride. The role of $\alpha_{1}$-adrenergic receptors in the respiratory airways it's still not definite and might be a study focus in more structures studies in future.

\section{Conflict of interest}

The authors declare no conflict of interest.

\section{References}

1. Rudner LX, Berkowitz DE, Booth JV, et al. Subtype specific regulation of human vascular alpha1-adrenergic receptors by vessel bed and age. Circulation 1999; 100: 2336-43.

2. Mathur SK, Sharma AK, Mathur R, et al. A short term comparative study of effects of alpha-adrenoreceptor blocker (Terazosin) and beta-adrenoreceptor blocker (Celiprolol) an respiratory parameters in mild-to-moderate hypertensive patients. Int J Sci Res 2014, 3: 266-9.

3. Malerba M, Agabiti-Rosei M. Respiratory effects of antihypertensive agents acting on alpha adrenergic receptors. Recenti Prog Med 1991; 82: 682-5.

4. Cazzola M, Page CP, Rogliani P, Matera MG. Beta2-agonist therapy in lung disease. Am J Respir Crit Care Med 2013; 187: 690-6.

5. Pera T, Penn RB. Bronchoprotection and bronchorelaxation in asthma: new targets, and new ways to target the old ones. Pharmacol Ther 2016; 164: 82-96.

6. Zamel N, Faraco EZ, De Freitas FM. Effects of norepinephrine and isoprenaline on the airway resistance of patients with chronic bronchial obstruction. Thorax 1966; 21: 333-6.

7. Dinh Xuan AT, Chaussain M, Regnard J, Lockhart A. Pretreatment with an inhaled alpha1-adrenergic agonist methoxamine, reduces exercise-induced asthma. Eur Respir J 1989; 2: 409-14.

8. Sanchez I, Koster JD, Wolstein R, Chernick V. Effect of racemic epinephrine and salbutamol on clinical score and pulmonary mechanics in infants with bronchiolitis. J Pediatr 1993; 122: 145-51.

9. Van Mieghem W, Stevens E, Billiet L. Phentolamine therapy in severe chronic asthmatiform bronchitis. Respiration 1981; 42: 184-7.

10. Shiner RJ, Mohlo MI. Comparison between alpha-adrenergic antagonist and a beta2-adrenergic agonist in bronchial asthma. Chest 1983; 83: 602-6.

11. Campbell SC. Effects of alpha-adrenergic blockade with phentolamine on airway function in asthma. Ann Allergy 1982; 49: 135-8.

12. Williams B, MacDonald TM, Morant S, et al. Spironolactone versus placebo, bisoprolol, and doxazosin to determine the optimal treatment for drug-resistant hypertension (PATHWAY-2): a randomised, double-blind, crossover trial. Lancet 2015; 386: 2059-68.
13. Sica DA. Doxazosin and congestive heart failure. Congest Heart Fail 2002; 8: 178-84.

14. Fusco F, Palmieri A, Ficarra V, et al. Alpha1-blockers improve benign prostatic obstruction in men with lower urinary tract smptoms: a systematic review and metaanalysis of urodynamic studies. Eur Urol 2016; 69: 1091-101.

15. Torimoto K, Hirao Y, Matsuyoshi H, et al. Alpha1-adrenergic mechanism in diabetic urethral dysfunction in rats. J Urol 2005; 173: 1027-32.

16. Biernacki W, Flenley DC. Doxazosin, a new alpha-1-antagonist drug, controls hypertension without causing airways obstruction in asthma and COPD. J Hum Hypertens 1989; 3: 419-25.

17. Itskovitz HD. Alpha 1-blockade for the treatment of hypertension: a megastudy of terazosin in 2214 clinical practice settings. Clin Ther 1994; 16: 490-504.

18. Sirak TE, Jelic S, Le Jemtel TH. Therapeutic update: non-selective beta- and alpha- adrenergic blockade in patients with coexisting chronic obstructive pulmonary disease and chronic heart failure. J Am Coll Cardiol 2004; 44: 497-502.

19. Vincent J, Dachman W, Blaschke FT, Hoffman BB. Pharmacological tolerance to alpha1-adrenergic receptor antagonism mediated by terazosin in humans. J Clin Investig 1992; 90: 1763-8.

20. Awan NA, Lee G, De Maria AN, Mason DT. Ambulatory prazosin treatment of chronic congestive heart failure development of late tolerance reversible by higher dosage and interrupted substitution therapy. Am Heart J 1981; 101: 541-7.

21. Attanasi A, Consilvio NP, Rapino D, et al. Bronchial hyperresponsiveness to mannitol, airway inflammation and asthma control test in atopic asthmatic children. Arch Med Sci 2016; 12: 137-44.

22. Thomson NC, Daniel EE, Hargreave FE. Role of smooth muscle alpha1-receptors in nonspecific bronchial responsiveness in asthma. Am Rev Respir Dis 1982; 126: 521-5.

23. Chapman N, Chen CY, Fujita T, et al. Time to re-appraise the role of alpha-1 adrenoreceptor antagonists in the management of hypertension? J Hypertens 2010; 28: 1796-803. 